Review

\title{
Modern scleral contact lenses: A review
}

\author{
Eef van der Worp ${ }^{a}$, Dina Bornman ${ }^{b}$, Daniela Lopes Ferreira ${ }^{c}$, Miguel Faria-Ribeiro ${ }^{c}$, \\ Nery Garcia-Porta ${ }^{c}$, José M. González-Meijome ${ }^{\mathrm{c}, *}$ \\ a Pacific University, College of Optometry, OR, USA \\ ${ }^{\mathrm{b}}$ College of Optometry, University of the Free State, Bloemfontein, South Africa \\ ${ }^{\mathrm{c}}$ Clinical and Experimental Optometry Research Laboratory (CEORLab) - Center of Physics (Optometry), School of Sciences, University of Minho, \\ Braga, Portugal
}

\section{A R T I C L E I N F O}

Article history:

Received 25 August 2013

Received in revised form 1 January 2014

Accepted 3 February 2014

\section{Keywords:}

Scleral contact lenses

Indications and fitting methods

Limbal and anterior scleral shape

Scleral lens performance

Adverse events

\begin{abstract}
A B S T R A C T
Scleral contact lenses (ScCL) have gained renewed interest during the last decade. Originally, they were primarily used for severely compromised eyes. Corneal ectasia and exposure conditions were the primary indications. However, the indication range of ScCL in contact lens practices seems to be expanding, and it now increasingly includes less severe and even non-compromised eyes, too.

All lenses that partly or entirely rest on the sclera are included under the name ScCL in this paper; although the Scleral Lens Education Society recommends further classification. When a lens partly rests on the cornea (centrally or peripherally) and partly on the sclera, it is called a corneo-scleral lens. A lens that rests entirely on the sclera is classified as a scleral lens (up to $25 \mathrm{~mm}$ in diameter maximum). When there is full bearing on the sclera, further distinctions of the scleral lens group include mini-scleral and large-scleral lenses.

This manuscript presents a review of the current applications of different ScCL (all types), their fitting methods, and their clinical outcomes including potential adverse events. Adverse events with these lenses are rare, but the clinician needs to be aware of them to avoid further damage in eyes that often are already compromised. The use of scleral lenses for non-pathological eyes is discussed in this paper.
\end{abstract}

(c) 2014 Published by Elsevier Ltd on behalf of British Contact Lens Association.

\section{Introduction}

Scleral contact lenses ( $\mathrm{ScCL}$ ) were linked to the first applications of contact lenses at the end of the nineteenth century $[1,2]$. However, corneal lenses and later soft contact lenses made ScCL nearly obsolete for a long period of time. The therapeutic advantages of ScCL continued to be reported in the peer-reviewed literature in the 1960s [3,4] but only a few specialized practitioners were fitting ScCL on a regular basis.

However, in the last few years, more companies have entered the ScCL market, and this was reflected in the research activity in this area. These lenses demonstrated therapeutic potential in their ability to successfully fit most patients with distorted corneas that were intolerant to other forms of vision correction including piggyback, hybrid or corneal gas permeable lenses [5]. For these reasons, these lenses are also known as "medically necessary contact lenses." Tan et al. showed that $69 \%$ of their 517 eyes fitted with

\footnotetext{
* Corresponding author at: Department of Physics (Optometry), School of Science, University of Minho, 4710-057 Gualtar, Braga, Portugal. Tel.: +351 253604072.

E-mail address: jgmeijome@fisica.uminho.pt (J.M. González-Meijome).
}

ScCL had previously failed with other contact lenses [6,7]. Most of these patients would probably have been referred for a corneal transplant. Several reports show the potential of ScCL to delay or prevent surgery $[8,9]$, which has an important impact on the costs involved in the health care of these patients [10]. Modern ScCL are an increasingly important part of the rigid gas permeable fittings in several countries.

\section{Search criteria}

A search was performed in PubMed on the 18th of November 2013 using different combinations of keywords as searching criteria. The outcomes are presented in Table 1. The most specific combination was represented by the junction of several keywords and reported a total of 102 papers, of which $86.7 \%$ were directly related to the field of ScCL. However, the sensitivity was quite low, retrieving only $36.7 \%$ of those references of interest. Instead, using a more generic combination of "scleral contact lens," a total of 458 references were retrieved. In this case, despite a low specificity (only $36.7 \%$ of the references were relevant for the field of clinical application of $\mathrm{ScCL}$ ), the sensitivity was higher because up to 68 papers 
Table 1

Different combinations of searching criteria, number of articles retrieved and specificity (\% of articles directly related with the field) and sensitivity *assuming 162 as the $100 \%$ of interest.

\begin{tabular}{lrll}
\hline Search criteria & $N$ & $\begin{array}{l}\text { \% Related } \\
\text { (specificity) }\end{array}$ & $\begin{array}{l}\text { \% Related not } \\
\text { detected } \\
\text { (sensitivity) }\end{array}$ \\
\hline $\begin{array}{l}\text { "Scleral lenses" } \\
\text { "Scleral contact lens" }\end{array}$ & 2495 & N.R & N.R \\
$\begin{array}{l}\text { "Semiscleral contact lens" or } \\
\text { "semiscleral contact lenses" }\end{array}$ & 441 & $36.7 \%$ & $100 \%$ \\
$\begin{array}{l}\text { "Semiscleral lens" } \\
\text { "Mini scleral contact lens" }\end{array}$ & 5 & $100 \%$ & $96.9 \%$ \\
$\begin{array}{l}\text { "Corneoscleral contact lens" } \\
\text { "Corneoscleral contact lens" or }\end{array}$ & 7 & $100 \%$ & $96.9 \%$ \\
$\begin{array}{l}\text { "Corneoscleral contact lenses" } \\
\text { "Scleral contact lens" }\end{array}$ & 29 & $100 \%$ & $95.7 \%$ \\
$\begin{array}{l}\text { "Scleral contact lens" or "scleral } \\
\text { contact lenses" or "corneoscleral } \\
\text { contact lenses" }\end{array}$ & 39 & $100 \%$ & $82.1 \%$ \\
$\begin{array}{l}\text { "Scleral contact lens" or "scleral } \\
\text { contact lenses" or "corneoscleral } \\
\text { contact lenses" or "mini scleral } \\
\text { contact lens" }\end{array}$ & 102 & $86.7 \%$ & $75.9 \%$ \\
\hline
\end{tabular}

N.R: not reported.

relevant to the field and not retrieved in the previous search were now obtained. Main confounders in the search were phakic lenses and vitreo-retinal surgery topics that included the words "scleral" and "lenses" simultaneously.

Using the combination suggested as the most sensitive and specific, almost 100 publications were retrieved. Fig. 1 illustrates the yearly rate of publications among those retrieved in the PubMed database during the last 50 years using this combination of terms.

\section{Historical overview}

The origins of contact lenses are intrinsically linked to scleral lenses. In fact, the first known contact lenses fitted to the eye were scleral lenses produced 125 years ago and made of blown glass shells [1]. The introduction of molding techniques for the glass lenses by Dallos in 1936 and the introduction of plastics for contact lenses in the 1940s by workers such as Feinbloom, Obrig and Gyoffry were important breakthroughs for the development of this lens modality, according to Tan et al. [6].

These lenses could now be lathe-cut in a much more accurate manner to mimic the anterior shape of the eye. The use of oxygen permeable lenses, as first described by Ezekiel in 1983 [11], was another breakthrough, since these brought major improvements

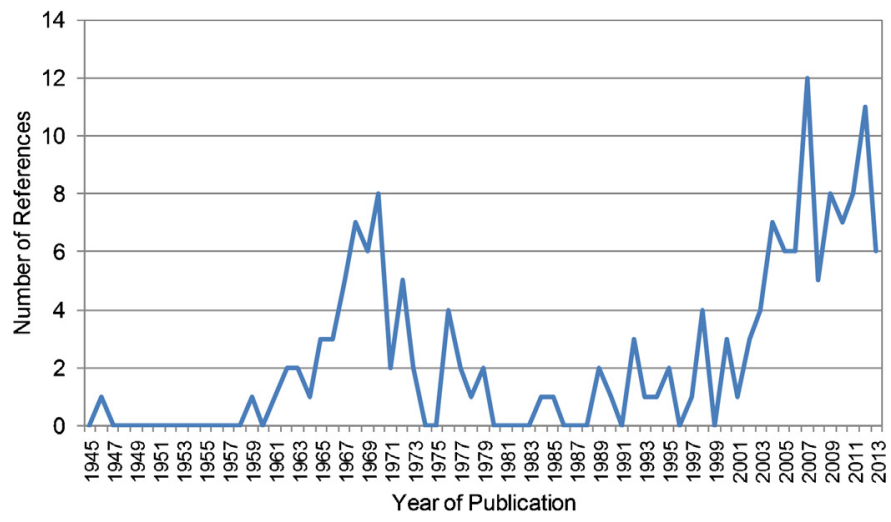

Fig. 1. Publication rate (yearly) in the field of scleral contact lenses as retrieved from the National Library of Medicine search engine (www.pubmed.com) by April 2013 using the following combination of keywords: "scleral contact lens" and after excluding the non-related references $(n=162)$. in ocular health. Lyons et al. developed the impression-molded process for fitting rigid gas permeable ScCL in the late 1980s [12]. The subsequent development of the smaller, corneal gas permeable lenses and later of soft lenses temporarily stopped further development of ScCL fitting. But the ScCL is now fully back on the agenda as an option for more challenging eyes, with many ScCL designs currently available to practitioners including back toric, quadrant specific and bifocal lens designs.

A few years ago, only a handful of very specialized lens fitters around the world were capable of fitting ScCL successfully, and only a few manufacturers were making ScCL. Now many contact lens manufacturers offer ScCL designs. Improved manufacturing processes allow for better design, more reproducibility and decreased costs. Additionally, better lens materials contributed to better ocular health, longer wearing time and ease of lens fit. Recently introduced special websites and organizations are devoted to ScCL. Conferences and the ophthalmic literature are frequently reporting on ScCL fitting. It is in the interest of the patient that more practitioners familiarize themselves with the ScCL modality to provide best optical correction and fit available for the more challenging eyes.

\section{Scleral lens designs}

\subsection{Oxygen supply to the cornea}

ScCL are presently manufactured in highly oxygen permeable rigid gas permeable materials [13]. Current materials allow high levels of oxygen to pass through the lens compared to early PMMA lenses [14]. Despite this, ScCL create a stagnant, thick tear layer depending on the lens type. Typically, the larger the lens design, the more tear clearance behind the lens is - or can be - created. Corneal edema is not commonly reported in ScCL wear. Pullum and Stapleton looked at central corneal swelling in four normal subjects wearing sealed scleral contact lenses for three hours. The lenses used were of $\mathrm{Dk} 32,59$, and 115 with thicknesses of $0.15,0.30$, 0.60 , and $1.20 \mathrm{~mm}$. For a scleral lens thickness of $0.6 \mathrm{~mm}$ in a material with a Dk of 115 , the mean central corneal swelling induced was less than 3\%, they concluded [14]. But according to theoretical estimations, tear film layers thicker than $250 \mu \mathrm{m}$ may induce edema under open eye conditions [15], in combination with a given thickness $(350 \mu \mathrm{m})$ and the maximum Dk value of the rigid gas permeable lens material available ( $\mathrm{Dk} 150>$. Following this estimation, as well as clinical experience, overnight wear of ScCLs should not be considered. Exceptions include if the state of the condition allows no other alternative, and the limitation of hypoxia is accepted as a risk factor [16]. Post-radiotherapy complications, Stevens-Johnson disease, and congenital or post-surgical lid defects have been some of the conditions contemplated by Tappin et al. for overnight ScCL wear [17], or persistent epithelial defects as reported by Rosenthal et al. [18].

\subsection{Classification and nomenclature}

Several different classification schemes for ScCL have been used in recent years, which have induced a similar diversity of names assigned to the different large diameter rigid gas permeable lenses. Van der Worp [19] and Jedlicka et al. [20] used similar criteria for mini-scleral (15.0-18.0 mm) and large-scleral/full-scleral lenses (18.1-25.0 $\mathrm{mm}$ and over), but not for the smaller semi-scleral and corneo-scleral lenses.

Recently (August 2013), the Scleral Lens Education Society (SLS) has recommended internationally recognized nomenclature for describing scleral lenses according to size and fit characteristics. Below is the recommendation of the SLS, which is summarized in 
Table 2

Nomenclature for describing scleral contact lenses according to size and fit characteristics.

\begin{tabular}{lll}
\hline Lens type & Subdivision & Bearing \\
\hline Corneal & & $\begin{array}{l}\text { Lens rests entirely on the } \\
\text { cornea }\end{array}$ \\
\hline Corneo-Scleral & & $\begin{array}{l}\text { Lens rests partly on the } \\
\text { cornea, partly on the sclera }\end{array}$ \\
\hline Scleral & $\begin{array}{l}\text { Mini-scleral } \\
\text { Lens is up to } 6 \mathrm{~mm} \text { larger } \\
\text { than HVID } \\
\text { Large-scleral } \\
\text { Lens is more than } 6 \mathrm{~mm} \\
\text { larger than HVID }\end{array}$ & $\begin{array}{l}\text { Lens rests entirely } \\
\text { on the sclera }\end{array}$ \\
\hline
\end{tabular}

HVID: horizontal visible iris diameter.

Table 2. Within the scope of the present review, the aim is to adhere to this nomenclature.

After considering input from a number of sources, the SLS recommends internationally recognized nomenclature for describing scleral lenses according to size and fit characteristics. This task is difficult due to the large number of naming schemes by individuals, manufacturers, and distributors. The goals are to simplify and generalize the nomenclature. According to the SLS recommendations, the bearing of the lens is the defining feature in scleral lens terminology. Simply put, if a lens rests completely on the cornea, it is called a corneal lens. A lens that partly rests on the cornea (centrally or peripherally), and partly on the sclera is called a corneo-scleral lens. A lens that rests entirely on the sclera, is a scleral lens no matter how large that lens is. The Scleral Lens Education Society advises against using diameter classification in scleral lens nomenclature, to avoid confusion (for instance in cases of extremely large or small eyes). Lens designs that are classified as corneo-scleral by diameter, sometimes rest entirely on the sclera. In the recommended nomenclature, these are referred to as "scleral lenses" even though they have relatively small diameters. When there is full bearing on the sclera, further distinctions of the scleral lens group include mini-scleral and large-scleral lenses. These distinctions emphasize differences in central corneal clearance and other fitting characteristics. As an example, a lens that is $6 \mathrm{~mm}$ larger than the horizontal visible iris diameter (e.g. has up to $3 \mathrm{~mm}$ of bearing on the sclera on each side of the lens) is classified as a mini-scleral lens. A lens that is more than $6 \mathrm{~mm}$ larger than the visible iris diameter is classified as a large-scleral lens. An $18 \mathrm{~mm}$ lens that bears exclusively on the sclera is a miniscleral lens on an eye with a corneal diameter of $12 \mathrm{~mm}$. A lens larger than $18 \mathrm{~mm}$ for the same eye is a large-scleral lens.

From Table 1 it is evident that the most frequent single nomenclature is "scleral contact lens;" this term represents only $24.1 \%$ of the publications of interest in the field. Within the scope of the present review, we aim to adhere to this nomenclature. It is followed by "corneo-scleral contact lens", "mini scleral contact lens" and "semi scleral contact lens". "Large scleral" will be considered as equivalent to the term full scleral used previously by other authors. The term semi-scleral is not considered in this new definition by the SLS.

\section{Fitting approaches}

Scleral lens fitting requires a totally different approach from that of other lenses. Compared to corneal lenses, corneal topography is not very useful as the lens rests entirely in the scleral region [21]. In the absence of quantitative information, several strategies have attempted to overcome this limitation. Impression techniques were first introduced by Lyons et al. in the late 1980s to mold PMMA plastic lenses and later rigid gas permeable materials. Meanwhile, several qualitative techniques have attempted to define the corneoscleral transition shape, but this region was not accurately defined until recently with the advent of anterior segment optical coherence tomography (OCT) [22,23].

\subsection{Impression techniques}

Although not very commonly used in modern contact lens practice, impression techniques have been utilized successfully for many years $[12,24]$. With this technique, a mold is made of the anterior ocular surface (the positive cast). Specialized equipment is needed to perform this procedure, whereby local anesthetics are normally required. Of this impression, a negative mold is created. Typically dental material, or an alternative, is used in recreating the anterior ocular surface shape. This positive cast can be sent to a specialized manufacturer to produce a scleral lens. These lenses follow the shape of the anterior surface precisely, and the impression retains its shape indefinitely so the lens can be reproduced at a later time.

In the past, ocular plaster molding techniques were described as invasive, messy and time consuming. The biggest downside of the method may be that heat was required in manufacturing the lens, which basically limited this technique to PMMA materials. Recently, however, ocular molding is having a resurgence as contact lenses are getting bigger and the desire for scleral information is not met with current imaging technology. An updated version of molding, using a special type of polyvinyl siloxane polymer, has re-entered the market. It is a relatively fast procedure that does not hurt the eye. The mold is then digitized and used in fitting the contact lens.

The fact that impression lenses may closely follow the shape of the anterior eye has been described as an advantage (a reported on in Section 5.3 in this paper). Another advantage of the system is that the practitioner does not need expensive fitting sets. In addition, there still may be a need to perform impression molding in cases of markedly disfigured eyes or for custom-fitted ocular prostheses.

\subsection{Preformed lenses}

At present, using a trial set to fit ScCL is the most commonly used method. This usually involves applying several lenses with varying vault, radius, power or diameter. Pecego et al. have recently reported an average of 3 lenses (range 1-8) needed to successfully fit the Jupiter Scleral Lens with diameters ranging from 14.8 to $20.2 \mathrm{~mm}$ in 107 patients with irregular corneas [5]. The periphery of the ocular surface has been found to be quite complex, and the use of toric haptic zones could potentially improve fitting success. Visser et al. were the first to report on toric scleral lens designs, showing that a marked increase in patient satisfaction was reported after switching from spherical to back-surface toric designs [25]. Additionally, toric lenses provide better rotational stabilization [26], which might improve comfort and allow for the incorporation of astigmatic and higher order aberration correction with these lenses. Others have tried to correlate corneal topographic data with sclera base curve, but the resulting correlations were too weak to significantly improve the predictability of scleral contact lens fitting [21]. New techniques, such as the aforementioned OCT [22] and wide field ocular surface height topographers [27], should significantly improve our knowledge of the corneo-scleral junction.

Another consideration in the fitting process is the option of incorporating fenestrations. The early designs made of PMMA needed to be fenestrated, and even some current corneo-scleral and scleral lenses include fenestrations. Fenestrations are generally considered as more of a source of complications such as bubble 
Table 3

Sample size and main indications for scleral lenses used in some of the larger studies published in the last 10 years in the peer-reviewed literature.

\begin{tabular}{|c|c|c|c|c|c|c|c|}
\hline & No. eyes & Ectasia (KC, PMD) & PK & Post-RS/irregular astigmatism & Scar & OSD & Other \\
\hline Visser et al. (2013) [36] & 213 & $56.8 \%$ & $13.6 \%$ & $13.1 \%$ & & $14.6 \%$ & $1.9 \%$ \\
\hline Dimit et al. (2013) [42] & 51 & $27.5 \%$ & & $17.6 \%$ & & $49 \%$ & $5.9 \%$ \\
\hline Baran et al. (2012) [38] & 118 & $72 \%$ & $18 \%$ & $10 \%$ & - & - & - \\
\hline Pecego et al. (2012) [5] & 107 & $53 \%$ & $30 \%$ & $7 \%$ & $3 \%$ & $3 \%$ & $4 \%$ \\
\hline Visser et al. (2007) [25,39] & 284 & $50.4 \%$ & $19.7 \%$ & $12.6 \%$ & & $8.8 \%$ & $8.5 \%$ \\
\hline Rosenthal and Croteau (2005) [8] & 875 & $34 \%$ & $15 \%$ & $4 \%$ & $2 \%$ & $38 \%$ & $7 \%$ \\
\hline Pullum et al. (2005) [28] & 1560 & $59.9 \%$ & $18.7 \%$ & - & - & $11.3 \%$ & $10.1 \%$ \\
\hline
\end{tabular}

KC, keratoconus; PMD, pellucid marginal degeneration; OSD, ocular surface disease.

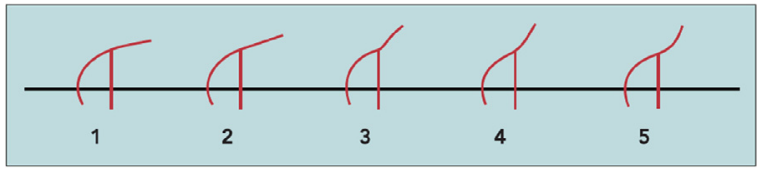

Fig. 2. Transition profiles from cornea to sclera (Courtesy of Daniel Meier/die Kontaktlinse).

formation than as a problem solving technique [28] and are not used on a regular basis. Table 3 shows a summary of different studies addressing different types of large diameter contact lenses for different conditions, their parameters and main outcomes.

\subsection{The role of limbal and anterior scleral shape in scleral lens fitting}

To fit scleral lenses, knowledge of the limbal and anterior scleral shape, which is the landing zone of scleral lenses, may be of interest, but relatively little has been reported on this topic. One of the few articles on limbal and scleral shape can be found in a German contact lens journal. Meier, a Swiss eye care practitioner, defines in die Kontaktlinse in 1992 different transition profiles from cornea to sclera. He describes five different models: a gradual transition from cornea to sclera, in which the scleral portion is either convex (profile 1) or tangential (profile 2), or a marked transition in which again the scleral portion can be either convex (profile 3) or tangential (profile 4). As a fifth option, he describes a convex corneal shape with a concave scleral shape (profile 5) in Fig. 2 [29].

The profiles in the Meier scale are decreasing in sagittal depth, in which profile number 1 has the highest sagittal height and profile number 5 has the lowest sagittal height - an important parameter for fitting scleral lenses. The studies by Meier, and another study published in die Kontaktlinse by Rott-Muff et al., tried to identify how often the different profiles were observed in the general population. The study results were remarkably similar: profile 2 (gradual-tangential) followed by profile 3 (marked-convex) were respectively the number one and two in occurrence, followed by profile 1 (gradual-convex) [30]. Profiles 4 and 5, marked-tangential and convex-concave, were seen minimally, with the latter almost nonexistent. The question of how accurately these profiles can be subjectively rated by practitioners was also addressed in an article in die Kontaktlinse by Bokern et al. a few years later [31]. The authors found a repeatability of only $54 \%$ using 73 investigators. For some profiles, the repeatability was much lower.

Current scleral lens designs have benefited from the knowledge of the ocular surface topography obtained from optical coherence tomography (OCT) [23], which can describe the ocular surface beyond the $9 \mathrm{~mm}$ usually covered by conventional corneal topographers or the $12 \mathrm{~mm}$ covered by Scheimpflug cameras. Studies at Pacific University College of Optometry investigated the shape of the anterior surface of the eye in eight meridians in normal eyes by using the Visante (Zeiss) anterior segment OCT to develop an average eye model. A limitation of OCT in its standard modality is that it can measure only up to $16.0 \mathrm{~mm}$ of the anterior ocular surface. But if the instrument is slightly decentered, easily up to $20.0 \mathrm{~mm}$ and further can be imaged [32,33].

The Pacific University studies measured the corneal-scleral tangential angle between $10.0 \mathrm{~mm}$ and $15.0 \mathrm{~mm}$ (defined in this study as the limbal angle) as well as the angle from $15.0 \mathrm{~mm}$ to $20.0 \mathrm{~mm}$ (the scleral angle) in 96 eyes of 48 normal subjects, all taken in reference to the horizontal plane (1289 angles were measured in total); see Fig. 3 for a graphical display of the results.

The results from the Pacific University study indicate that eye care practitioners should not expect the limbal area and the anterior sclera to necessarily have the concave/convex shapes that would be expected based on theoretical consideration when fitting/designing a scleral lens. It is suggested that using tangent angles rather than using curves (or using very flat curves) may be appropriate in many cases when fitting scleral lenses. But large individual limbal and anterior scleral shape differences occur, even within the same eye, among meridians.

What these results also indicate is that on the average eye, the ocular surface beyond the cornea is non-rotationally symmetrical in nature. It appears that in the average eye, the entire nasal portion typically is flatter compared to the rest (see Fig. 4). Marriott, a British optometrist, in 1966 was probably the first to describe this after looking at molds taking from eyes to manufacture haptic lenses [34]. From the Pacific studies, it is evident that this effect (of a flatter nasal appearance) is less for the limbal angles than for the scleral angles. The limbal angles are in roughly the same range and were not found to be statistically significantly different from each other. But in the scleral ring this is not the case: especially between the nasal region and the temporal-inferior section, remarkable differences exist. It appears that on the scleral angles, the inferior segment is almost the "benchmark," while the nasal angles are lower in comparison and the temporal angles are higher, with statistically significant differences between those. The increasing peripheral asymmetry may be related to the insertion of the extra-ocular muscles following the "spirale de Tillaux" [35], the authors hypothesize.

Based on the results described above, it appears that for the average eye, non-rotationally symmetrical lenses such as toric and quadrant specific lenses, both of which are commercially available, could be necessary to optimally respect the shape of the eye. This is especially the case if the ScCL diameter goes beyond the $15.0 \mathrm{~mm}$ mark. The same effect has been reported based on clinical experience: the non-spherical nature of the sclera has been described previously by Visser et al., using large-scleral lenses [26]. Visser et al. also recently published a paper on a new lens design, a toric scleral lens with a tangential periphery that they successfully fitted in 213 eyes of 144 patients. The fitting and performance characteristics of this new lens were clear and effective for both the health professional and the patients, the authors concluded [36].

Recently, Hall et al. published two papers investigating the corneo-scleral junction (CSJ) in normal eyes and found similar results. First, the mean $\mathrm{CSJ}$ tended to be sharpest at the nasal side (and became progressively flatter at the inferior, temporal 


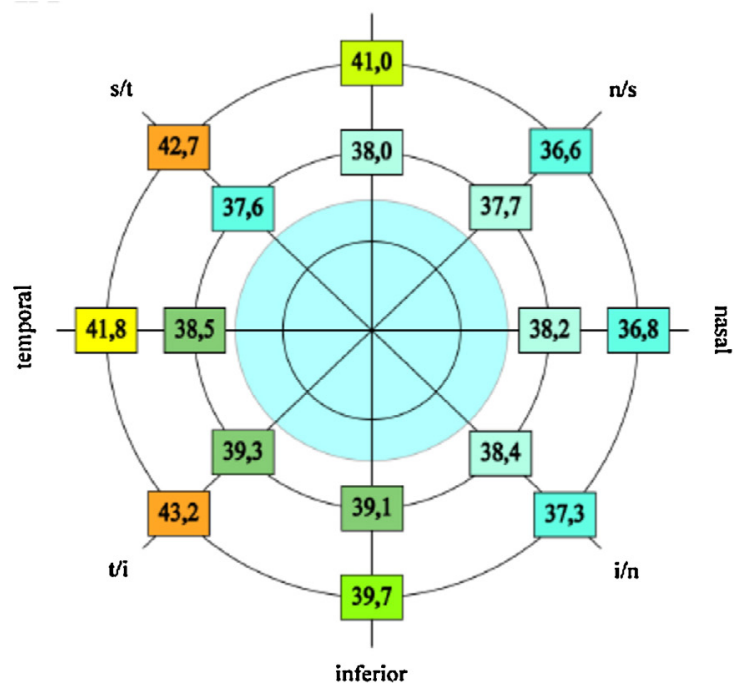

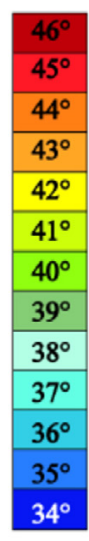

inferior

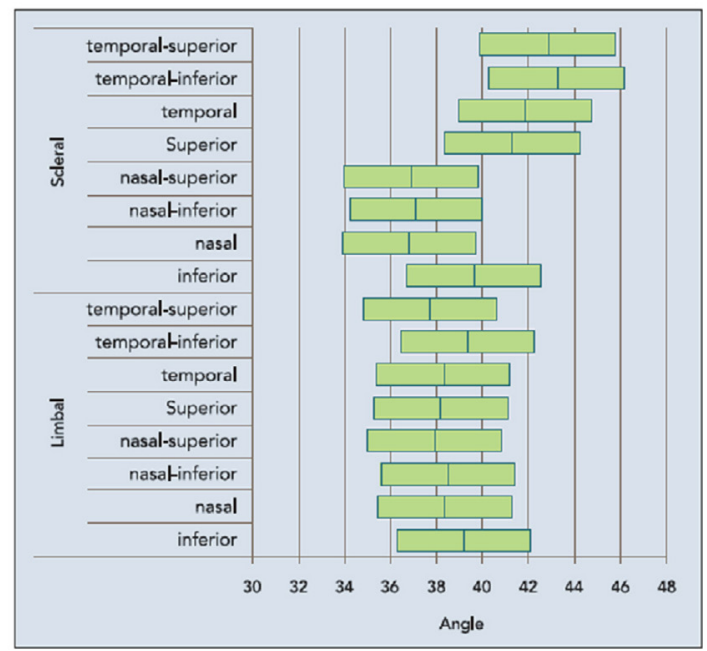

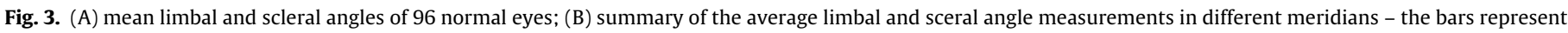
the mean (center line) and $84 \%$ confidence intervals (kindly provided by Pacific University - the Scleral Shape Study).

and superior junctions in their studies), while in many cases they reported that the CSJ angles were within $1^{\circ}$ of $180^{\circ}$, indicating almost tangential extensions of the peripheral cornea to form the sclera [22,37].

Gemoules published the first paper on using OCT data to design scleral lenses. This option may be the preferred method in the future considering the large individual differences and nonrotationally symmetrical nature of the sclera [23]. Certainly the future is promising in using such technologies to optimize the fitting of ScCL over the complex and highly variable perilimbal and scleral areas (Fig. 5).

\section{Indications of scleral contact lenses}

ScCL are usually not a first option, but are typically prescribed when other lenses do not provide adequate visual acuity or are not well tolerated. In a study by Baran et al., patients dispensed with the Boston prosthetic device (PROSE) had a visual acuity with habitual correction of 20/70 on average [38]. While the main goal is to improve visual acuity when fitting ScCL, it is accepted that the increase in visual acuity is significantly higher for eyes with corneal surface irregularities compared to those with ocular surface disease (OSD) [39].

The motivation for fitting ScCL is typically divided into vision improvement, ocular surface protection and support, and a segment that includes fitting ScCL for sports and cosmetic purposes. While some studies report only on the application of these lenses in severe ocular surface disease for surface protection [40], others include only the application for corneal irregularities [41]. Finally, others report on a wider scope of ocular conditions including irregularity of the ocular surface such as in keratoconus, postsurgical ectasia or post keratoplasty, among others as illustrated in Table 3. Pullum reported in 2005 an increase in cases with primary corneal ectasia, corneal transplants and OSD from the 1980s and 1990s, while other former indications for ScCL such as high myopia and aphakia have decreased steadily in the literature during the last three decades [28].

\subsection{Vision improvement}

Severe stages of corneal ectasic disorders have been reported as an indication for large scleral lens designs. Indeed, those peerreviewed publications presenting the larger samples clearly show that corneal ectasia is the primary indication for ScCL fitting, followed by post-penetrating keratoplasty patients $[5,25,28]$. Despite this, the use of ScCL for the keratoconus correction in the general population is still low. Shneor et al. in 2012 reported that in a large cohort of 244 keratoconic patients, $78.7 \%$ wore contact lenses, of whom $4.2 \%$ wore scleral lenses [8]. Table 2 shows a comparison of the percentage of fittings by conditions for the 5 larger studies conducted in the last 10 years.

Post-surgical contact lens fitting can be challenging when severe irregularities are present. This is the case with penetrating keratoplasty and severe corneal ectasia. In these cases, the vault afforded by corneo-scleral lenses is usually insufficient, and mini-scleral or large-scleral lenses are often required. Large sclerals are also needed for the most severe cases in which high vault is required due to excessive corneal elevation or severe corneal irregularities and

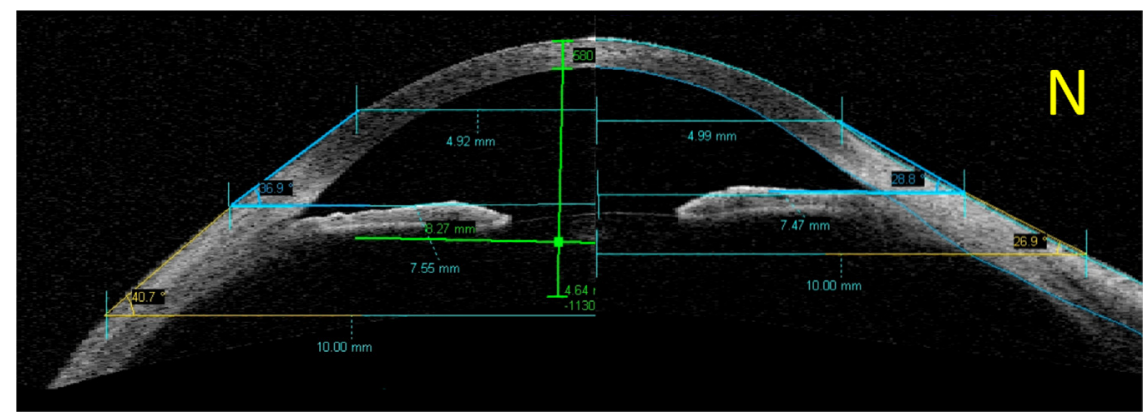

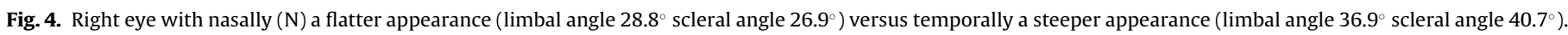

Please cite this article in press as: van der Worp E, et al. Modern scleral contact lenses: A review. Contact Lens Anterior Eye (2014), http://dx.doi.org/10.1016/j.clae.2014.02.002 

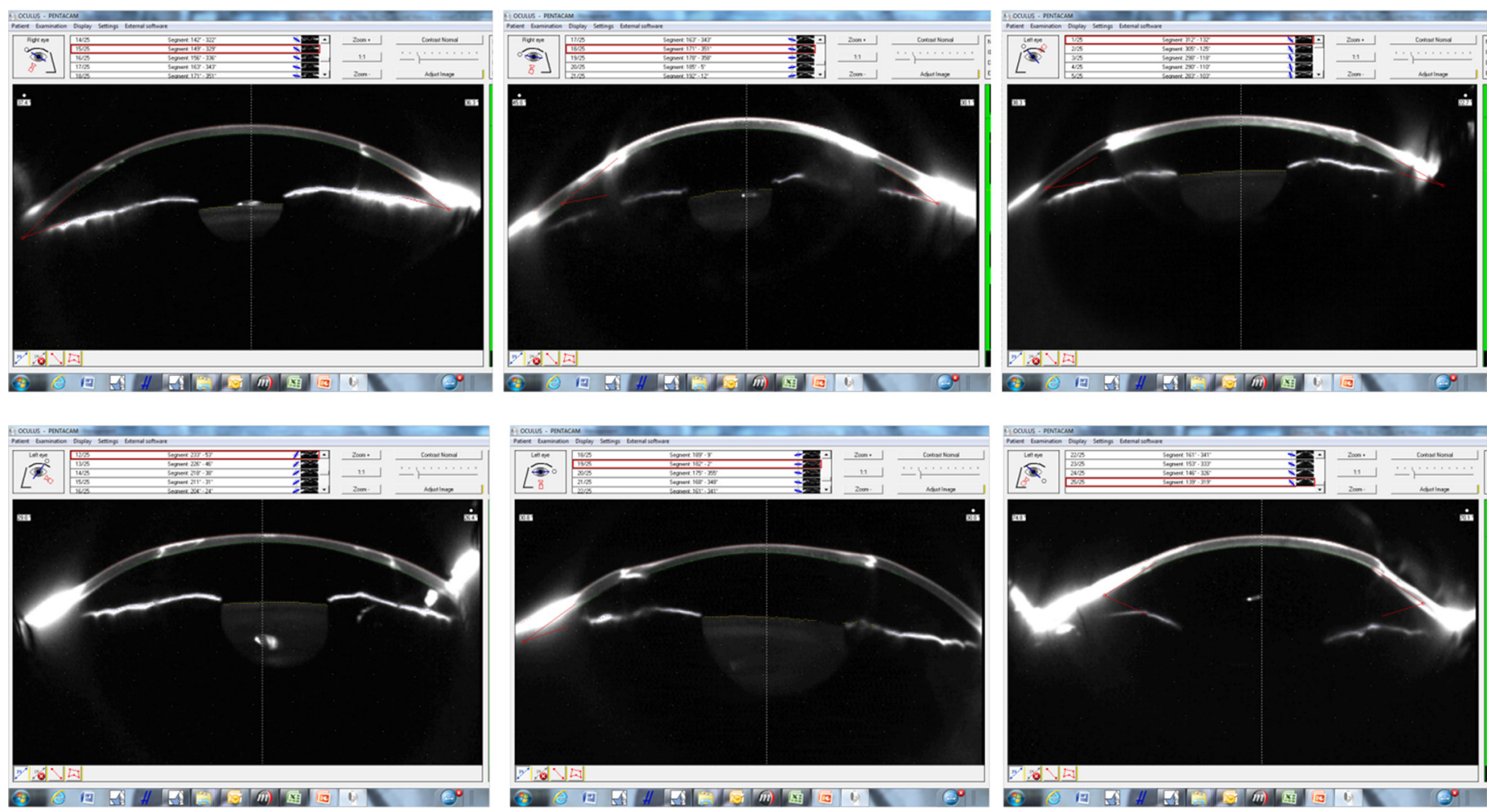

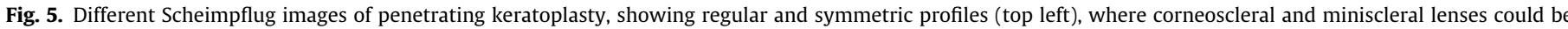
fitted, to very irregular and asymmetric profiles (bottom right), where miniscleral or large scleral lenses are usually needed.

asymmetries (Fig. 2). Mini-scleral and large-scleral lenses provide the advantage of maximizing the vault over the cornea, which is paramount in penetrating keratoplasty to protect the suture area from excessive touch. This might also be an advantage in intracorneal segment implantation for keratoconus; in such cases as the vault achieved prevents excessive compression of the thin corneal tissue over the implant, which can lead to recurrent corneal erosions when lenses are applied that touch the corneal surface.

ScCL contribute to a decrease in higher-order aberrations (HOA) in irregular corneas with different etiologies including keratoconus, post-penetrating keratoplasty and post-refractive surgery. Patients with ocular surface disease, also showed a significant reduction in HOA but lower than that observed in the other groups, as their baseline values were also much lower than in the groups of irregular corneas [43]. ScCL also offer very stable platforms for fine adjustment of design to improve visual quality. This was the approach in a recent case report of a keratoconus patient in whom the authors observed a visual improvement related to a decrease in higher order aberrations by adjusting the front surface eccentricity of the lens $[44,45]$. More sophisticated compensation of higher order aberrations might be possible with contact lenses, although decentration and movement are usually a limitation [46]. The limited movement of scleral lenses made them adequate platforms for the correction of highly aberrated eyes.

More recently, corneo-scleral and mini-scleral lenses have also been fitted in less severe cases to take advantage of the excellent comfort, corneal vaulting and centration afforded by these lenses. ScCL present several advantages over other contact lens correction options that also make them interesting platforms for the nondiseased eye. The large diameter of these lenses can potentially provide better comfort than corneal rigid gas permeable contact lenses. Their large diameter also results in excellent centration and stability, which makes these lenses good options when incorporating complex optical designs such as multifocal correction for presbyopia or customized visual corrections addressing higher order aberrations. Furthermore, scleral lenses also might be useful in high-tech applications such as augmented reality and other "future" applications (see also Section 6.3). However, in this domain of fitting the non-diseased eye, the balance between risk and benefit is less clear considering the unknown consequences of long-term tear stagnation [47] and perilimbal conjunctival compression in the normal eye.

\subsection{Ocular surface protection}

Severe ocular surface disease has been one of the primary indications for large ScCL for many years [24,40]. The rationale for using theses lenses is to provide ocular surface protection against dehydration while keeping the ocular surface moistened [48]. This approach has been successful even in pediatric patients with severe ocular surface disease [49].

Many exposure keratitis/ocular surface disease patients can particularly benefit from ScCL because of the retention of a fluid reservoir behind the scleral lens [42]. Sjögren's syndrome is a common ScCL indication. Under this category also fall conditions such as persistent epithelial corneal defects, Stevens-Johnson syndrome, graft versus host disease, ocular cicatricial pemphigoid, neurotrophic corneal disease and atopic keratoconjunctivitis. Surface disorders caused by chemical and thermal burns have been another indication for large ScCL.

Also, if lid closure is incomplete such as in eyelid coloboma, exophthalmus, ectropion, nerve palsies and after lid retraction surgery [28], a scleral lens may be a good option. In addition, in cases of trichiasis and entropion, ScCL have shown to be effective in protecting the ocular surface. In symblepharon, a ScCL can act as a device to maintain the fornix, for instance after chemical burns.

More recently, ScCL have also been used to deliver pharmaceuticals to the anterior surface for different reasons. One such indication is the application of antibiotics while the ocular surface recovers/heals, such as the treatment of persistent corneal 
epithelial defects with a ScCL and an antibiotic adjunct [18,50]. Jacobs et al. [51] discussed the possibility of using ScCL as a novel drug delivery system for bevacizumab for neovascularization. Also, the application of ScCL with low levels of sodium channel modulators has been proposed as a form of pain mediation [52].

\subsection{Cosmetics, sports and other indications}

Hand painted scleral lenses have been used for cosmetic purposes in a variety of cases [53], and painted lenses have also been used to reduce glare in aniridia and albinism [54], although this would technically fall under the vision improvement category rather than under cosmetic indications. Scleral lenses have also been used for cosmetic reasons in cases of a ptosis [55].

Scleral lenses may be helpful for those involved in active water sports such as water-polo or canoeing, diving and water skiing as well as for other vigorous sports activities or for those that involve exposure to dusty environments. Scleral lenses also are frequently used by the film industry to create special eye effects.

Another relevant aspect of scleral lens fitting is the possibility to reduce photophobia. Some patients with severe ocular surface diseases present a high degree of photophobia potentially related with the increase in light scattering at the damaged corneal surface. Romero-Rangel et al. have documented a marked reduction in photophobia in $75 \%$ of their patients treated with ScCL [40].

Finally, new applications for ScCL are under development, including augmented reality devices and magnifying devices for use in the military field or in the visual rehabilitation of low vision patients. The authors of this invention describe a $1.6 \mathrm{~mm}$ thick device containing a reflection system that, combined with the use of polarizing glasses, warrants a $2.8 \times$ magnification. The authors acknowledge the limitations of this approach in terms of oxygen permeability, and they declare they are investigating new solutions for gas transmission. They specifically refer to "air-channel structures for gas-permeability in future contact lens designs" [56].

\section{ScCL performance}

Defining success with ScCL fitting can be quite variable. When lenses are prescribed to correct irregular corneas, visual acuity is the primary goal. In this regard, several studies report significant increases in visual acuity with ScCL fitting. Table 4 presents a summary of the characteristics and main outcomes of several studies reported in the peer-review literature that evaluated anywhere from under 10 eyes up to over one thousand eyes.

Pullum et al., in one of the largest studies ever reported on ScCL, reported a visual acuity of $9 / 6$ or better in $78.7 \%$ of their patients fitted with ScCLs for ectatic and post-surgical irregular corneas.

Conversely, when the primary goal is surface protection in ocular surface disorders, visual acuity might be poorer but the condition will be considered successfully managed if providing pain and discomfort relief and preventing further worsening of the condition. The same study reported that only $29.9 \%$ of patients with OSD presented visual acuity $\geq 9 / 6$ [28]. Schornack et al., recently presented a study in which they evaluated the visual success of fitting ScCL in different ocular surface diseases. While the average VA improved in all conditions, this improvement was statistically significant for neurotrophic keratopathy, exposure keratopathy, graft versus host disease and limbal stem cell efficiency. For the remaining conditions including Salzmann's nodules, cicatrizing conjunctivitis, post-refractive surgery dry eye and Sjögren's Syndrome, the statistical power of the sample was not enough to demonstrate a significant improvement [57]. The Boston Foundation for Sight published a prospective study in which 80 patients of 101 recruited were successfully fitted; visual acuity data was reported for 79 patients ( 141 eyes) including 66 eyes with OSD and 75 eyes with ectasia/astigmatism. Up to $19 \%$ improved visual acuity by 2 or more lines in the OSD group while 55\% improved by two or more lines in the ectasia/astigmatism group. Visual acuity results were confirmed subjectively by the National Eye Institute Visual Functioning Questionaire (NEI FVQ-25) collected from 69 eyes [58].

Wearing time may be considered a good indicator of tolerance and success of the contact lens correction. Most of the studies listed in Table 4 report wearing times between 8 and $16 \mathrm{~h} /$ day $[40,41,59,60]$, although some report inferior times for some patients [61]. Considering the condition of most of the patients wearing these lenses, the need for the correction means that the time of "comfortable wear" could be a better indicator than solely the "time of wear" to account for the satisfaction of the patients. Subjective satisfaction and self-reported quality of life most likely best endorses the satisfactory performance of ScCL from the patients' standpoint $[25,40,38]$.

\section{Potential adverse events of scleral contact lenses}

\subsection{Non-severe adverse events}

Tan et al. reported several adverse events in their retrospective study of 517 eyes, most of them fitted with molded PMMA lenses. Adverse events included edema (7.4\%), corneal vascularization (13.3\%), abrasion (3.1\%) and papillary conjunctivitis (1.7\%) [6]. Despite being successfully used by many patients, complaints with modern ScCL are still quite common. Pecego et al. reported $20 \%$ of patients complained of difficulties with lens insertion or removal, $10 \%$ with visual disturbances including haze, blurriness or halos and $10 \%$ with discomfort or pain, among others [5].

It is also relevant to point out the potential effect of the absence of tear turnover. Rathi et al. have recently reported a decrease of 2 or more lines of visual acuity after $4 \mathrm{~h}$ of lens wear due to tear debris trapped behind the Boston Scleral Lens [62]. Gungor et al. described peripheral channels in that lens design to improve tear turnover [49]. Another alternative to deal with these issues is to remove the lenses once or twice a day and reinsert them, filling the tear reservoir with fresh non-preserved saline. Although this is somewhat inconvenient for the patient, the benefits in comfort, vision and safety might overcome such difficulties. Although this seems to be an approach followed by several clinicians, the peer-review literature does not report this strategy as frequently as might be expected, with only one of the papers reviewed reporting the need for a break from lens wear during the day as a way to improve lens performance [25].

\subsection{Severe adverse events}

It is unclear at this point whether the oxygen permeability of current materials used to manufacture ScCL is sufficient (see Section 4.2). In addition, the tear stagnation behind these lenses might contribute to higher rates of adverse events such as microbial keratitis, especially considering the already compromised status of most of the corneas. Rosenthal and Croteau reported the occurrence of four cases of microbial keratitis in patients wearing the Boston Scleral lens on an extended wear basis [8]. Compliance has also been implicated as the cause for a case of MK in a patient wearing ScCL for visual rehabilitation because of neurotrophic keratitis secondary to herpes simplex [65]. Other case reports included acute red eye in a keratoconus patient wearing a mini-scleral lens (diameter: $16.0 \mathrm{~mm}$ ) [66] and the event of infection in the form of polymicrobial keratitis [67]. 
Table 4

Lens characteristics and main outcomes of different studies addressing the fitting of ScCL.

\begin{tabular}{|c|c|c|c|c|c|c|c|}
\hline Author (year) & $\begin{array}{l}\text { Condition(s) number of } \\
\text { eyes age female:male }\end{array}$ & $\begin{array}{l}\text { Brand } \\
\text { (manufacturer) }\end{array}$ & $\begin{array}{l}\text { Lens type } \\
\text { (diameter) }\end{array}$ & $\begin{array}{l}\text { Follow-up } \\
\text { (mean) }\end{array}$ & Baseline VA & Post-fitting VA & Additional information \\
\hline \multirow[t]{2}{*}{$\begin{array}{l}\text { Dimit et al. } \\
(2013)[42]\end{array}$} & Keratoconus, DES & $\begin{array}{l}\text { PROSE (Boston } \\
\text { Foundation for } \\
\text { Sight) }\end{array}$ & Large scleral & & & & $\begin{array}{l}\text { Improve } 3 \text { logMAR lines in } \\
\text { the DES group }\end{array}$ \\
\hline & 51 eyes & & & & & & $\begin{array}{l}\text { Improve } 2 \text { lines in the } \\
\text { keratoconus group }\end{array}$ \\
\hline \multirow[t]{4}{*}{$\begin{array}{l}\text { Visser et al. } \\
(2013)[36]\end{array}$} & $\begin{array}{l}\text { Keratoconus, PK, OSD, } \\
\text { irregular astigmatism }\end{array}$ & $\begin{array}{l}\text { Visser } \\
\text { bitangential } \\
\text { scleral }\end{array}$ & $\begin{array}{l}20.5-21.5 \mathrm{~mm} \\
(5 \%)(20.0 \mathrm{~mm} \\
(76 \%)\end{array}$ & $\begin{array}{l}3 \text { weeks to } 1 \\
\text { year }(9.4 \\
\text { weeks })\end{array}$ & N.R. & $\geq 0.8$ in $62.9 \%$ & $\begin{array}{l}\text { Lower Dk materials in } \\
\text { smaller lenses, patients with } \\
\text { protein deposits and scratch } \\
\text { surfaces }\end{array}$ \\
\hline & 213 eyes & & $\begin{array}{l}18.5-19.5 \mathrm{~mm} \\
(19 \%)\end{array}$ & & & $\begin{array}{l}0.6-0.8 \text { in } \\
17.8 \%\end{array}$ & $\begin{array}{l}\text { Smaller sagittal depths to } \\
\text { improve insertion and } \\
\text { reduce post-lens debris }\end{array}$ \\
\hline & 47.7 years & & & & & $\begin{array}{l}0.4-0.6 \text { in } \\
10.8 \%\end{array}$ & $\begin{array}{l}77 \% \text { of lenses rated } 4 \text { or } 5 \text { in a } \\
1-5 \text { scale }\end{array}$ \\
\hline & $64: 80$ & & & & & & \\
\hline \multirow[t]{3}{*}{$\begin{array}{l}\text { Romero-Jiménez } \\
\text { (2013) [41] }\end{array}$} & Irregular cornea & $\begin{array}{l}\text { Rose K2 XL } \\
\text { (Menicon) }\end{array}$ & $\begin{array}{l}\text { Mini-scleral } \\
(13-16 \mathrm{~mm})\end{array}$ & 6-9 months & $\begin{array}{l}0.14 \text { (with } \\
\text { habitual CL) }\end{array}$ & 0.10 & $8-12 \mathrm{~h}$ of wear \\
\hline & 30 eyes & & & & & & $\begin{array}{l}1 \text { patient with corneal } \\
\text { abrasion on insertion }\end{array}$ \\
\hline & $33.8 \pm 13.8$ years & & & & & & $\begin{array}{l}1 \text { eye with conjunctival } \\
\text { injury during removal }\end{array}$ \\
\hline \multirow[t]{4}{*}{$\begin{array}{l}\text { Alipour et al. } \\
(2012)[61]\end{array}$} & $\begin{array}{l}\text { Moderate-to-severe dry } \\
\text { eye }\end{array}$ & $\begin{array}{l}\text { MSD } \\
\text { (Blanchard } \\
\text { Contact Lens } \\
\text { Inc.) }\end{array}$ & Mini-scleral & $\begin{array}{l}15-20 \text { months } \\
\text { (18.25 months) }\end{array}$ & $0.89 \log$ MAR & $0.21 \log$ MAR & 8 patients continued \\
\hline & 19 eyes & & $15.8 \mathrm{~mm}$ & & & & 5 patients discontinued \\
\hline & 42.4 & & & & & & $12-14 \mathrm{~h}$ wear in 6 eyes \\
\hline & $8: 5$ & & & & & & $5-7 \mathrm{~h}$ in 2 eyes \\
\hline \multirow[t]{3}{*}{$\begin{array}{l}\text { Baran et al. } \\
(2012)[38]\end{array}$} & $\begin{array}{l}\text { Keratoconus, PMD, } \\
\text { post-RSE }\end{array}$ & $\begin{array}{l}\text { PROSE (Boston } \\
\text { Foundation for } \\
\text { Sight) }\end{array}$ & N.R. & N.R. & $20 / 70$ & $\geq 20 / 40$ in $93 \%$ & 15 non-dispensed \\
\hline & 118 eyes & & & & & & $\begin{array}{l}\text { Significant increase in quality } \\
\text { of life Score NEI VFQ-25 }\end{array}$ \\
\hline & $\begin{array}{l}44 \pm 14.5 \text { years } \\
26: 33\end{array}$ & & & & & & \\
\hline \multirow[t]{4}{*}{$\begin{array}{l}\text { Kalwerisky et al. } \\
\text { (2012) [59] }\end{array}$} & Ocular burns & $\begin{array}{l}\text { PROSE (Boston } \\
\text { Foundation for } \\
\text { Sight) }\end{array}$ & N.R & $\begin{array}{l}4 \text { months to } 4.5 \\
\text { years }\end{array}$ & - & $8 \geq 20 / 70$ & $\begin{array}{l}\text { Scleral lens allows for } \\
\text { functional lid replacement } \\
\text { until reconstructive surgery } \\
\text { can be made }\end{array}$ \\
\hline & 8 eyes & & & & & $4 \geq 20 / 20$ & Wearing time: $16 \pm 5 \mathrm{~h} /$ day \\
\hline & $21-52$ & & & & & & 2 eyes developed MK \\
\hline & N.R. & & & & & & \\
\hline \multirow[t]{2}{*}{$\begin{array}{l}\text { Rathi et al. } \\
\text { (2012) [62] }\end{array}$} & $\begin{array}{l}\text { Keratoconus and OSD in } \\
\text { pediatrics }\end{array}$ & $\begin{array}{l}\text { PROSE (Boston } \\
\text { Foundation for } \\
\text { Sight) }\end{array}$ & $15.5-18.0 \mathrm{~mm}$ & N.R. & \multicolumn{2}{|c|}{$25 \%$ improved 2 lines } & $9 \mathrm{~h}$ of wear \\
\hline & $\begin{array}{l}20 \text { eyes } \\
12.8 \pm 2.7 \text { years }\end{array}$ & & & & \multicolumn{2}{|c|}{$75 \%$ improved more than 2 lines } & $\begin{array}{l}\text { VA decrease in } 45 \% \text { after } 4 \mathrm{~h} \\
\text { due to tear debris }\end{array}$ \\
\hline $\begin{array}{l}\text { Rathi et al. } \\
\text { (2011) [63] }\end{array}$ & $\begin{array}{l}\text { Keratoconus, } \\
\text { post-surgery and } \\
\text { Stevens-Johnson ( } 43 \\
\text { eyes) }\end{array}$ & $\begin{array}{l}\text { PROSE (Boston } \\
\text { Foundation for } \\
\text { Sight) }\end{array}$ & N.R. & $\begin{array}{l}1-60 \text { months } \\
(20.7 .6 \pm 21.2)\end{array}$ & 1.13 decimal & 0.29 decimal & $\begin{array}{l}3-6 \text { sessions to train } \\
\text { handling } \\
5 \text { out of } 15 \text { children were } \\
\text { dependent on parents to } \\
\text { insertion and removal }\end{array}$ \\
\hline $\begin{array}{l}\text { Shah-Desai et al. } \\
\text { (2011) [55] }\end{array}$ & $\begin{array}{l}\text { Blepharoptosis } \\
14 \text { eyes } \\
4: 6\end{array}$ & Unknown & N.R. & $1-40$ years & \multicolumn{2}{|c|}{$\begin{array}{l}\text { Palpebral aperture increased } \\
\text { from } 4.9 \text { to } 9.5 \mathrm{~mm}\end{array}$} & $\begin{array}{l}22-64 \% \text { considered good or } \\
\text { moderate cosmetic } \\
\text { improvement }\end{array}$ \\
\hline \multirow[t]{3}{*}{$\begin{array}{l}\text { Pecego et al. } \\
(2012)[5]\end{array}$} & $\begin{array}{l}\text { Keratoconus, post-PK, } \\
\text { scarring,... }\end{array}$ & $\begin{array}{l}\text { Jupiter scleral } \\
\text { lens (Visionary } \\
\text { Optics) }\end{array}$ & $14.8-20.2 \mathrm{~mm}$ & $3-17$ & N.R. & $\begin{array}{l}\text { Improved by } \\
3.2 \text { lines }\end{array}$ & 1-8 lenses needed \\
\hline & 107 eyes & & & & & & $\begin{array}{l}23 \% \text { abandoned over } 3 \\
\text { months }\end{array}$ \\
\hline & 47.5 years & & & & & & \\
\hline \multirow[t]{3}{*}{$\begin{array}{l}\text { Stason et al. } \\
(2010)[58]\end{array}$} & Ectasia/astigmatism, OSD & $\begin{array}{l}\text { PROSE (Boston } \\
\text { Foundation for } \\
\text { Sight) }\end{array}$ & N.R. & 6 months & $\geq 20 / 30$ (30\%) & $\begin{array}{l}\text { Improved by } 2 \\
\text { or more lines in } \\
19 \%(\text { OSD) and } \\
55 \% \text { (ectasia) }\end{array}$ & $\begin{array}{l}\text { Visual improvement more } \\
\text { likely in ectasia/astigmatism } \\
\text { and with better baseline VA. }\end{array}$ \\
\hline & 141 eyes & & & & $\begin{array}{l}20 / 40-20 / 60 \\
(32 \%)\end{array}$ & & $\begin{array}{l}21 \text { not fitted due to fitting } \\
\text { problems or not } \\
\text { improvement of VA. }\end{array}$ \\
\hline & 44 years & & & & $\leq 20 / 70(38 \%)$ & & \\
\hline
\end{tabular}

44 years 
Table 4 (Continued)

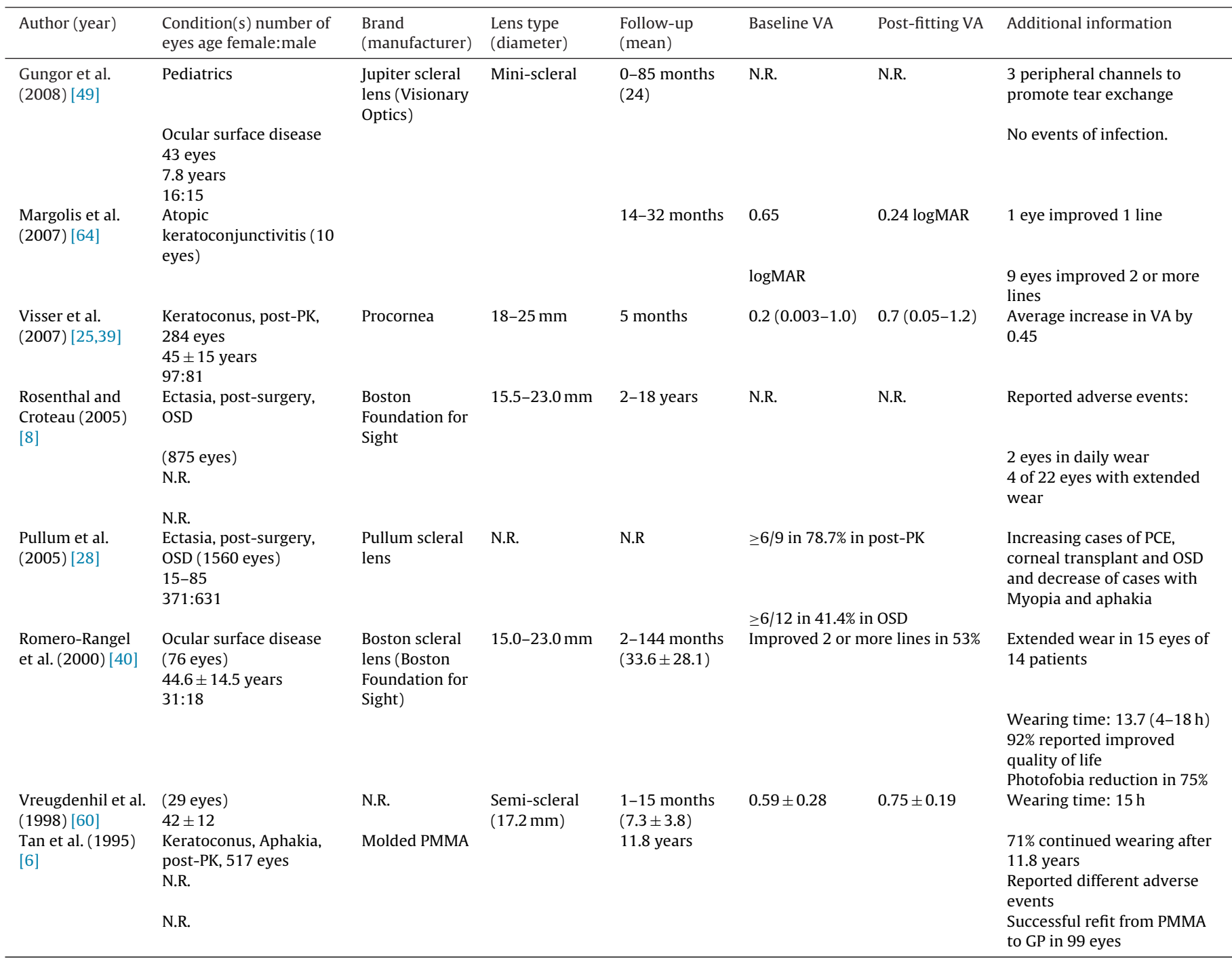

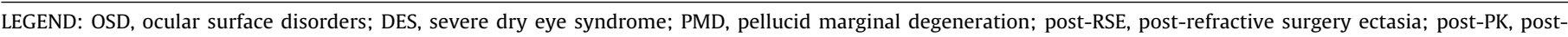
penetrating keratoplasty; PCE, primary corneal ectasia; MK, microbial keratitis.

In a case series of five patients in a US Army burn unit who suffered severe ocular burns, the authors reported two cases of microbial keratitis related to Pseudomonas and MRSA [59]. However, this is considered a non-standard situation in which many other co-morbidities are implicated. The occurrence of adverse reactions in uncompromised eyes wearing ScCL has not been commonly reported in the peer-review literature.

\section{Conclusion and future directions}

Most of the reports in the peer-review literature agree that ScCL are a good option for diseased corneas and ocular surfaces. However, limitations still exist that affect the widespread use of these contact lenses. Their fitting is mostly based on a steep learning curve, and the practitioner's experience plays a great role in success. Therefore, the fitting approach needs to be enhanced by developing more reliable instrumentation to define the pericorneal ocular surface topography with the aim of providing more objective pathways for fitting ScCL.

Most of the evidence developed so far is limited to relatively small clinical studies conducted by independent researchers, or to large cohort studies from practitioners and entities developing and fitting their own designs [68]. Thus, the actual efficacy and safety of modern ScCL in the hands of the average (or even the experienced) contact lens practitioner are unknown. For the domain of fitting the non-diseased eye, the balance between risk and benefit is less evident at this point than in diseased eyes, considering the unknown consequences of longterm scleral lens wear for the normal, healthy, eye versus the benefits in visual acuity gain or comfort. Although unavoidable possibly in certain conditions, extended wear of ScCL seems to be related with an increasing risk of bacterial keratitis.

ScCL represent a different paradigm in terms of physiological interaction with the ocular surface compared to other types of contact lenses as they limit the tear exchange underneath the lens [47]. In this domain a deeper knowledge of the biochemical changes in the homeostasis of the ocular surface during ScCL wear in the shortand long-term is desired. Assessment of the biochemical response at the ocular surface to monitor the inflammatory response in an objective manner might provide additional insight into the safety and efficacy of these devices.

Although desirable in certain conditions, extended wear of ScCL seems to be related with an increasing risk of bacterial keratitis. Other risks include non-compliance with care regimens. Compliance with care instructions seems to be paramount with ScCL, 
considering the already compromised nature of the cornea and the stagnant tear environment between the contact lens and the cornea.

New and fascinating applications for scleral lenses are awaiting the confirmation of their physiological compatibility with the ocular surface, not only for the diseased eye but also for healthy eyes. These include both new technological applications to be developed and also the optimization of visual outcomes by adjusting not only the compensation of lower order aberrations but also higher order aberrations.

\section{Acknowledgements}

The authors wish to thank Dr. Lynnette Johns for valuable input on this manuscript and Professor Patrick Caroline, Tina Graf \& the Pacific University for their contributions, particularly in the section dealing with the description of the sclera shape.

The authors declare that they do not have any proprietary or financial interest in any of the products mentioned in this article.

\section{References}

[1] Pearson RM. Karl Otto Himmler, manufacturer of the first contact lens. Cont Lens Anterior Eye 2007;30:11-6.

[2] Wollensak G. Otto Himmler: first manufacturer of lathe cut corneo-scleral lenses. Surv Ophthalmol 2004;49:374-5.

[3] Ridley F. Scleral contact lenses. Their clinical significance. Arch Ophthalmol 1963;70:740-5.

[4] Ridley F. Therapeutic uses of scleral contact lenses. Int Ophthalmol Clin 1962:2:687-716.

[5] Pecego M, Barnett M, Mannis MJ, Durbin-Johnson B. Jupiter scleral lenses: the UC Davis Eye Center experience. Eye Cont Lens 2012;38:179-82.

[6] Tan DT, Pullum KW, Buckley RJ. Medical applications of scleral contact lenses: 1. A retrospective analysis of 343 cases. Cornea 1995;14:121-9.

[7] Segal O, Barkana Y, Hourovitz D, Behrman S, Kamun Y, Avni I, Zadok D, et al. Scleral contact lenses may help where other modalities fail. Cornea 2003;22:308-10

[8] Rosenthal P, Croteau A. Fluid-ventilated, gas-permeable scleral contact lens is an effective option for managing severe ocular surface disease and many corneal disorders that would otherwise require penetrating keratoplasty. Eye Cont Lens 2005;31:130-4.

[9] Smiddy WE, Hamburg TR, Kracher GP, Stark WJ. Keratoconus. Contact lens or keratoplasty? Ophthalmology 1988;95:487-92.

[10] Shepard DS, Razavi M, Stason WB, et al. Economic appraisal of the Boston ocular surface prosthesis. Am J Ophthalmol 2009;148:860-8.

[11] Ezekiel D. Gase permeable haptic lenses. J Br Cont Lens Assoc 1983;6:158-61.

[12] Lyons CJ, Buckley RJ, Pullum K, Sapp N. Development of the gas-permeable impression-moulded scleral contact lens. A preliminary report. Acta Ophthalmol Suppl 1989;192:162-4.

[13] Bleshoy H, Pullum KW. Corneal response to gas-permeable impression scleral lenses. J Brit Cont Lens Assoc 1988:2:31-4.

[14] Pullum KW, Stapleton FJ. Scleral lens induced corneal swelling: what is the effect of varying Dk and lens thickness? CLAO J 1997;23:259-63.

[15] Michaud L, van der Worp E, Brazeau D, Warde R, Giasson CJ. Predicting estimates of oxygen transmissibility for scleral lenses. Cont Lens Anterior Eye 2012;35:266-71.

[16] Smith GT, Mireskandari K, Pullum KW. Corneal swelling with overnight wear of scleral contact lenses. Cornea 2004;23:29-34.

[17] Tappin MJ, Pullum KW, Buckley RJ. Scleral contact lenses for overnight wear in the management of ocular surface disorders. Eye (Lond) 2001;15:168-72.

[18] Rosenthal P, Cotter JM, Baum J. Treatment of persistent corneal epithelial defect with extended wear of a fluid-ventilated gas-permeable scleral contact lens. Am J Ophthalmol 2000;130:33-41.

[19] van der Worp E. A guide to scleral lens fitting. Vol. Books and Monographs. Book 4. Forest Grove, Oregon.: Pacific University; 2011 http://commons.pacificu.edu/ mono/54

[20] Jedlicka J, Johns LK, Byrnes SP. Scleral contact lens fitting guide. Cont Lens Spectrum 2010;3:0-36

[21] Schornack MM, Patel SV. Relationship between corneal topographic indices and scleral lens base curve. Eye Cont Lens 2010;36:330-3.

[22] Hall LA, Young G, Wolffsohn JS, Riley C. The influence of corneoscleral topography on soft contact lens fit. Invest Ophthalmol Vis Sci 2011;52:6801-6.

[23] Gemoules G. A novel method of fitting scleral lenses using high resolution optical coherence tomography. Eye Cont Lens 2008;34:80-3.

[24] Pullum K, Buckley R. Therapeutic and ocular surface indications for scleral contact lenses. Ocul Surf 2007;5:40-8.

[25] Visser ES, Visser R, van Lier HJ, Otten HM. Modern scleral lenses part II: patient satisfaction. Eye Cont Lens 2007;33:21-5.
[26] Visser ES, Visser R, van Lier HJ. Advantages of toric scleral lenses. Optom Vis Sc 2006;83:233-6.

[27] Jongsma FH, de BJ, Hendrikse F, Stultiens BA. Development of a wide field height eye topographer: validation on models of the anterior eye surface. Optom Vis Sci 1998;75:69-77.

[28] Pullum KW, Whiting MA, Buckley RJ. Scleral contact lenses: the expanding role. Cornea 2005;24:269-77.

[29] Meier D. Das cornea-scleral-profil - ein kriterium individueller kontactlinsenanpassung. Die Kontaktlinse 1992;10:4-10.

[30] Rott-Muff D, Keller U, Hausler M, Spinell M. Das cornea-skleral-profil und seine auswirkingen auf die form von weischlinsen. Die Kontaktlinse 2001;5: 26-34.

[31] Bokern S, Hoppe M, Bandlitz S. Genauigkeit und wiederholbarkeit bei der klassifizierung des corneo-skleral profils. Die Kontaktlinse 2013;7(8):26-8.

[32] van der Worp E, Graf T, Caroline P. Exploring beyond the borders. Cont Lens Spectrum 2010;6:26-32.

[33] Kojima R, Caroline P, Graff T, et al. Eye shape and scleral lenses. Cont Lens Spectrum 2013;3:8-43.

[34] Marriott PJ. An analysis of the global contours and haptic contact lens fitting. Br J Physiol Opt 1966;23:1-40.

[35] de Gottrau P, Gajisin S, Roth A. Ocular rectus muscle insertions revisited: an unusual anatomic approach. Acta Anat (Basel) 1994;151:268-72.

[36] Visser ES, Van der Linden BJ, Otten HM, Van der Lelij A, Visser R. Medical applications and outcomes of bitangential scleral lenses. Optom Vis Sci 2013;90:1078-85.

[37] Hall LA, Hunt C, Young G, Wolffsohn J. Factors affecting corneoscleral topography. Invest Ophthalmol Vis Sci 2013;54:3691-701.

[38] Baran I, Bradley JA, Alipour F, Rosenthal P, Le HG, Jacobs DS. PROSE treatment of corneal ectasia. Cont Lens Anterior Eye 2012;35:222-7.

[39] Visser ES, Visser R, van Lier HJ, Otten HM. Modern scleral lenses part I: clinica features. Eye Cont Lens 2007;33:13-20.

[40] Romero-Rangel T, Stavrou P, Cotter J, Rosenthal P, Baltatzis S, Foster CS. Gas-permeable scleral contact lens therapy in ocular surface disease. Am J Ophthalmol 2000;130:25-32.

[41] Romero-Jimenez M, Flores-Rodriguez P. Utility of a semi-scleral contact lens design in the management of the irregular cornea. Cont Lens Anterior Eye 2013

[42] Dimit R, Gire A, Pflugfelder SC, Bergmanson JP. Patient ocular conditions and clinical outcomes using a PROSE scleral device. Cont Lens Anterior Eye 2013;36:159-63.

[43] Gumus K, Gire A, Pflugfelder SC. The impact of the Boston ocular surface prosthesis on wavefront higher-order aberrations. Am J Ophthalmol 2011;151:682-90.

[44] Jagadeesh DMR. Visual performance with changes in eccentricity in PROSE device: a case report and review. J Optom 2013:6, http://dx.doi.org/10.1016/j.optom.2013.04.001.

[45] Hussoin T, Le HG, Carrasquillo KG, Johns L, Rosenthal P, Jacobs DS. The effect of optic asphericity on visual rehabilitation of corneal ectasia with a prosthetic device. Eye Cont Lens 2012;38:300-5.

[46] Lopez-Gil N, Castejon-Mochon JF, Fernandez-Sanchez V. Limitations of the ocular wavefront correction with contact lenses. Vision Res 2009;49: 1729-37.

[47] Ko L, Maurice D, Ruben M. Fluid exchange under scleral contact lenses in relation to wearing time. Br J Ophthalmol 1970;54:486-9.

[48] KokJH, Visser R. Treatment of ocular disorders and dry eyes with gas-permeable scleral lenses. Cornea 1992:11:518-22.

[49] Gungor I, Schor K, Rosenthal P, Jacobs DS. The Boston scleral lens in the treatment of pediatric patients. J AAPOS 2008;12:263-7.

[50] Lim P, Ridges R, Jacobs DS, Rosenthal P. Treatment of persistent corneal epithelial defects with overnight wear of a prosthetic device for the ocular surface. Am J Ophthalmol 2013;156:1095-101.

[51] Jacobs DS. Update on scleral lenses. Curr Opin Ophthalmol 2008;19: 298-301.

[52] Rosenthal P. Evolution of an ocular surface prosthesis. Cont Lens Spectrum 2009;12:28-40.

[53] van der Worp E. Scleral lens case report series: beyond the corneal borders. Books and monographs. Book 5. Forest Grove, Oregon: Pacific University; 2012 http://commons.pacificu.edu/mono/5

[54] Millis EAW. Scleral and prostetic lenses. In: Medical contact lens practice. Elsevier; 2005. p. 121-8.

[55] Shah-Desai SD, Aslam SA, Pullum K, Beaconsfield M, Rose GE. Scleral contact lens usage in patients with complex blepharoptosis. Ophthal Plast Reconstr Surg 2011;27:95-8.

[56] Tremblay EJ, Stamenov I, Beer RD, Arianpour A, Ford JE. Switchable telescopic contact lens. Opt Express 2013;21:15980-6.

[57] Schornack M, Baratz KH, Maguire L, Patel SV. Scleral lenses in the management of ocular surface disease. In: ARVO meeting, poster 4715. 2012

[58] Stason WB, Razavi M, Jacobs DS, Shepard DS, Suaya JA, Johns L, et al. Clinica benefits of the Boston ocular surface prosthesis. Am J Ophthalmol 2010;149: 54-61.

[59] Kalwerisky K, Davies B, Mihora L, Czyz CN, Foster JA, DeMartelaere S. Use of the Boston ocular surface prosthesis in the management of severe periorbital thermal injuries: a case series of 10 patients. Ophthalmology 2012;119: 516-21.

[60] Vreugdenhil W, Geerards AJ, Vervae CJ. A new rigid gas-permeable semi-scleral contact lens for treatment of corneal surface disorders. Cont Lens Anterior Eye 1998;21:85-8 
[61] Alipour F, Kheirkhah A, Jabarvand BM. Use of mini scleral contact lenses in moderate to severe dry eye. Cont Lens Anterior Eye 2012;35:272-6.

[62] Rathi VM, Mandathara PS, Vaddavalli PK, Srikanth D, Sangwan VS. Fluid filled scleral contact lens in pediatric patients: challenges and outcome. Cont Lens Anterior Eye 2012;35:189-92.

[63] Rathi VM, Mandathara PS, Dumpati S, Vaddavalli PK, Sangwan VS. Boston ocular surface prosthesis: an Indian experience. Indian J Ophthalmol 2011:59:279-81.

[64] Margolis R, Thakrar V, Perez VL. Role of rigid gas-permeable scleral contact lenses in the management of advanced atopic keratoconjunctivitis. Cornea 2007;26:1032-4.
[65] Zimmerman AB, Marks A. Microbial keratitis secondary to unintended poor compliance with scleral gas-permeable contact lenses. Eye Cont Lens 2014;40:1-4

[66] Bruce AS, Nguyen LM. Acute red eye (non-ulcerative keratitis) associated with mini-scleral contact lens wear for keratoconus. Clin Exp Optom 2013;92:245-8

[67] Fernandes M, Sharma S. Polymicrobial and microsporidial keratitis in a patient using Boston scleral contact lens for Sjogren's syndrome and ocular cicatricial pemphigoid. Cont Lens Anterior Eye 2013;36:95-7.

[68] Pullum KW, Buckley RJ. A study of 530 patients referred for rigid gas permeable scleral contact lens assessment. Cornea 1997;16:612-22.

Please cite this article in press as: van der Worp E, et al. Modern scleral contact lenses: A review. Contact Lens Anterior Eye (2014), http://dx.doi.org/10.1016/j.clae.2014.02.002 